\title{
Development of Dual Fuel Mitsubishi UE Diesel Engine UEC-LSGi
}

\begin{abstract}
With the recent growing interest in natural gas fueled ships around the world, demands for marine diesel engines that serve this need are rapidly increasing. This paper explains the approach to dual fuel engines that Mitsubishi has taken with its UE low speed 2-stroke diesel engine named the UEC-LSGi. The UEC-LSGi has a high pressure natural gas injection system and runs on pilot fuel oil and natural gas. With natural gas combustion, UEC-LSGi delivers the same heat efficiency as that of a diesel engine while also reducing both $\mathrm{NOx}$ and $\mathrm{CO}_{2}$ emissions, which is a great advantage with regard to $\mathrm{NOx}$ regulations and EEDI. The UEC-LSGi operates in the same way as traditional diesel engines, that is, by means of diffusion combustion. Therefore, the UEC-LSGi can run in the gas mode without load limitations. Since natural gas does not contain sulfur and since the pilot fuel is used only minimally, UEC-LSGi emits very little SOx.
\end{abstract}

\section{1.はじめに}

船舶から排出される大気污染物質 (NOx, SOx) や 温室効果ガス $\left(\mathrm{CO}_{2}\right)$ に関する規制は年々厳しくなっ ている.図1に示すIMO 規制では, NOx排出率は 2011 年から Tier I 規制值より約 15\%削減されており (Tier II)，2016 年からは ECA（排出規制海域; Emission Control Area）内では約 80\%削減される (TierIII). SOxについても燃料中の $\mathrm{S}$ 分濃度を制限寸ることで段 階的に強化されている.

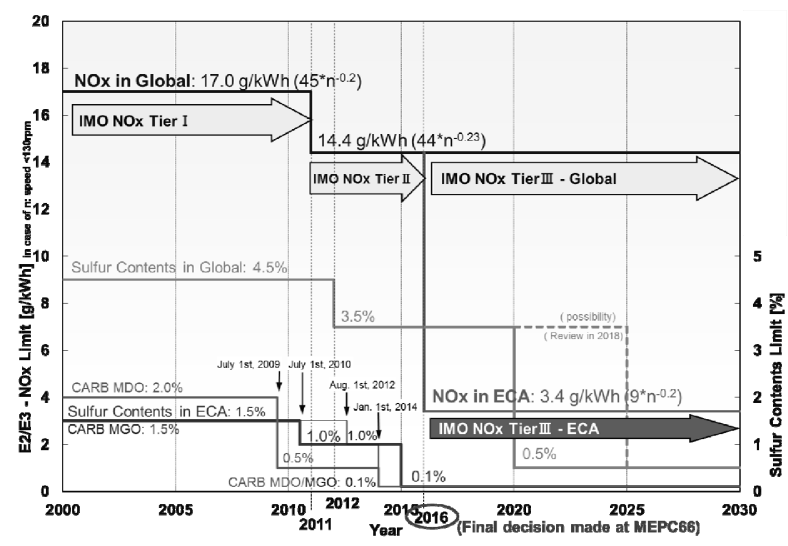

図 1 IMO 規制
図 2 に示寸 EEDI (Energy Efficiency Design Index）規制では，温室効果ガスである $\mathrm{CO}_{2}$ の排出 の抑制を目的に 2015 年 1 月から段階的に強化され ていくこととなる.

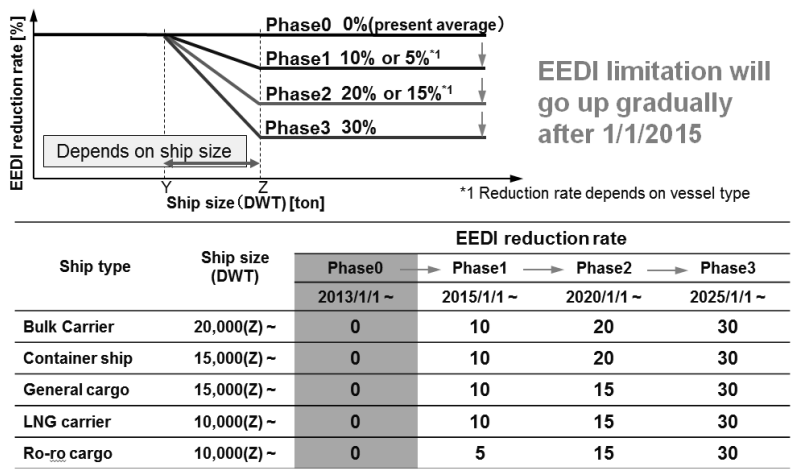

図 2 EEDI 規制

また，燃料油価格の上昇を背景に，経済的理由から も，省エネ技術が必須のものとなってきている.

排ガス規制と燃料油価格の将来的動向を考えると， これからの船舶は大気污染物質や温室効果ガスの排出 が少なく，かつ安価な燃料を使用できることが益々求 められていく。これらの課題に対して，LNG を燃料 とするガスエンジンは 2 つ優位性を持っている. 第 一に，重油焚きのディーゼルエンジンと比べて NOx 
と $\mathrm{CO}_{2}$ の排出が少なく $\mathrm{SOx}$ はほとんど排出しないこ と, 第二に, 将来の LNG 価格は重油よりも安価に予測 されており運航コストの低減が見込まれることである. 更に重油と LNG の両方を使用可能なデュアルフュー エルエンジン (DF 機関) では, 燃料価格の動向に応 じて最適な燃料を選択することが可能となる，本稿で は当社のデュアルフューエル UE 機関 UEC-LSGi ${ }^{(1)(2)}$ の開発について説明する.

\section{UEC-LSGi}

\section{1 UEC-LSGi の DF 方式}

DF 機関には図 3 に示すように, 予混合方式 DF (Premixed DF) と直噴 (GI) 方式DF (Gas Injection DF）の 2 つの方式があり，UEC-LSGi は直噴（GI） 方式を採用している。直噴方式のメリットは， LNG 使用時も重油使用時と同じ拡散然焼となるため, メ夕 ン価などのガス組成に依らず安定した燃焼が可能で, メタンスリップも無く, 重油焚きディーゼルと同等の 性能を維持できることである. 但し, 高圧 (約 300bar) のガス供給が必要で, また予混合方式に比べると NOx 排出率が高く,IMO-NOx TierIII規制值を満足するに は $\mathrm{EGR}^{(2) ま た は ~} \mathrm{SCR}^{(2)(3)}$ の適用が必要となる。

予混合方式のメリットは, 低圧（約 5～15bar 前後） のガス供給で運転可能であり，予混合燃焼となるため Tier III規制達成可能なレベルの低い NOx 排出率が実 現出来ることである，但し，予混合気を圧縮する方式 であるため，燃焼がメタン価などのガス組成の影響を 受け易く, 圧縮行程中の過早着火を防止するために負 荷制限が必要となる場合があり，重油焚きディーゼル や直噴方式 DF よりも圧縮比を下げる必要があるため 熱効率が低下する．またメタンスリップが発生する.

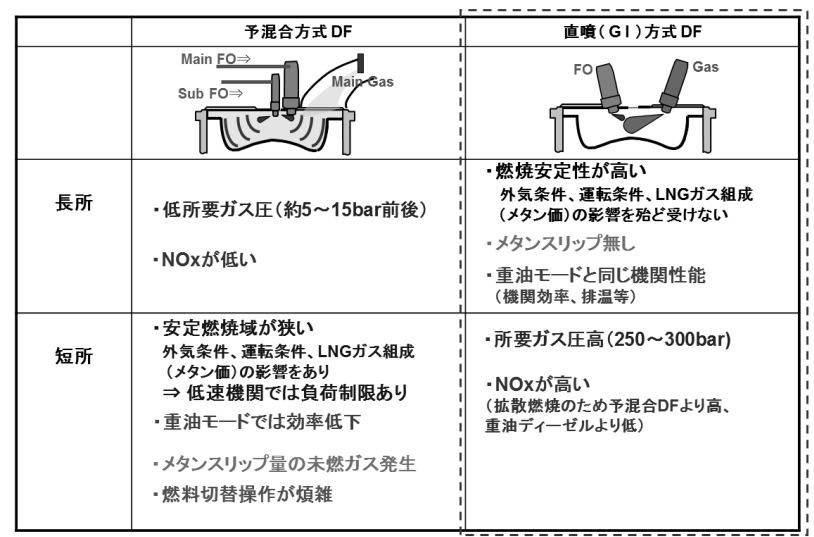

図 $3 \mathrm{DF}$ 方式の比較

\section{2 UEC-LSGi の機関設計}

UEC-LSGi の本体構造は従来のディーゼル機関と 同一で，図 4 に示寸ように，高圧の作動油で駆動され るガス噴射弁 (GIV) ,ガス蓄圧ブロック (GAB)，ガ ス供給ラインなどを追加している. UEC-LSGi の電子 制御システムは, UEC Eco-engine ${ }^{(4)}$ の制御システムを ベースに開発されたもので, 燃焼監視システム (CMS) を追加している. 燃焼圧力は CMS で常時監視されて おり, 燃焼の異常を検知した場合は直ちにガス運転(ガ スモード）から重油運転（ディーゼルモード）へ切替 えることで安全性を高めている.

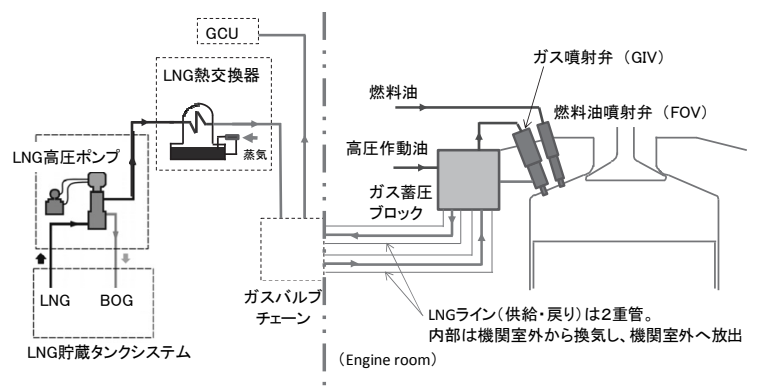

図 4 UEC-LSGi のシステム構成

\section{3 LNG 供給システム}

UEC-LSGi は直噴方式DFであるため図 5 に示寸高 圧 LNG ポンプを使用しており，ガス漏れを防止し検 知するため, 図 6 に示寸二重管や吸引ファン， $\mathrm{HC}$ セ ンサなどの安全装置を備えている，ガス漏れを検知す ると，自動的にガス供給が遮断され，エンジンの運転 はガスモードからディーゼルモードへ切替わる.

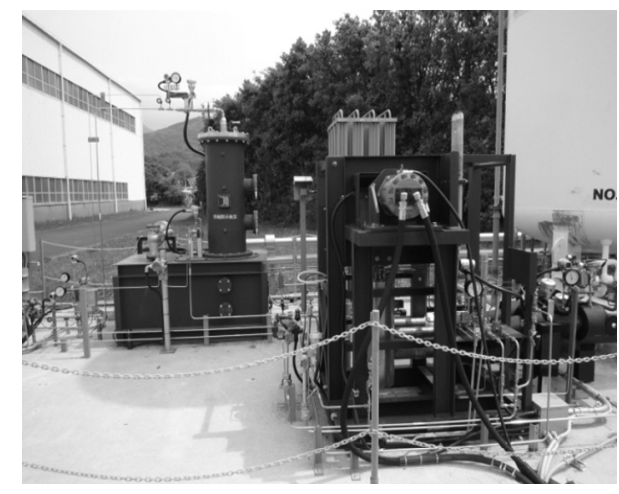

図 5 高圧 LNG ポンプと熱交換器 


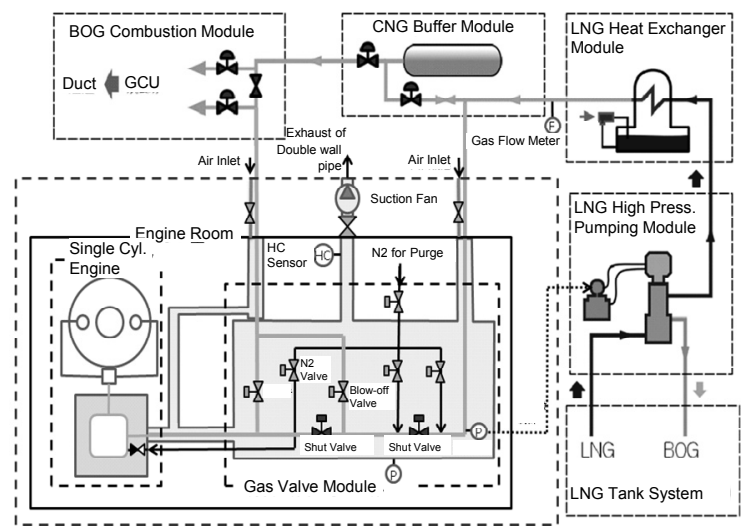

図 6 LNG 供給ラインと安全装置

\section{3. ガス噴射システムの試験結果}

図 7 に示す UEC-LSGi ガス噴射システムは，ガス 噴射弁 (Gas Injection Valve: GIV)，ガスゲート弁

(Gas Gate Valve: GGV)，ガス蓄圧ブロック（Gas Accumulator Block: GAB) 等で構成されている. 試 験台にて 6000 時間相当の耐久試験を実施し，バルブ シートや本体強度等に問題のないことを確認した。

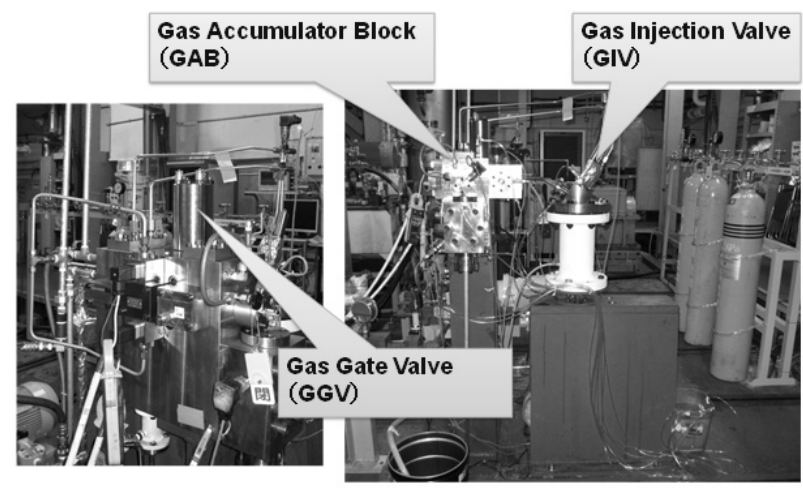

図 7 ガス噴射システムの耐久試験設備

\section{UEC-LSGi 運転試験結果}

図 8 に示す UEC-LSGi 試験機関はシリンダ径 $330 \mathrm{~mm}$ の単筒機関で，本機を用いて DF 機関の基本 性能確認を実施した.

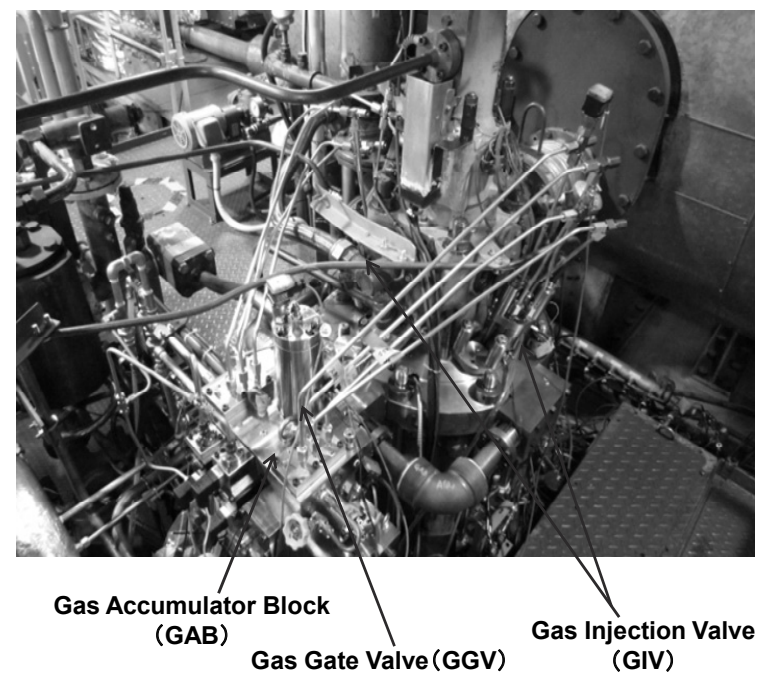

図 8 UEC-LSGi 試験機関

$75 \%$ 負荷での性能計測結果を図 9 に示す.ディーゼ ルモードに対して，熱効率は同等，NOx は約 $25 \%$ 低 減, $\mathrm{CO}_{2}$ は約 $25 \%$ 低減する結果が得られた。 過渡応答 の確認結果を困 10 に示す。荒天時を想定した負荷変 動（60～80\%負荷）に対して，ガス供給量の制御によ り回転数の変動が抑えられており良好な追従性を確認 した.また，パイロット燃料の噴射量を全投入熱量の 1\%まで低減させた試験も実施し（図 11）運転できる ことを確認した。長期而久性の評価を実施中である.

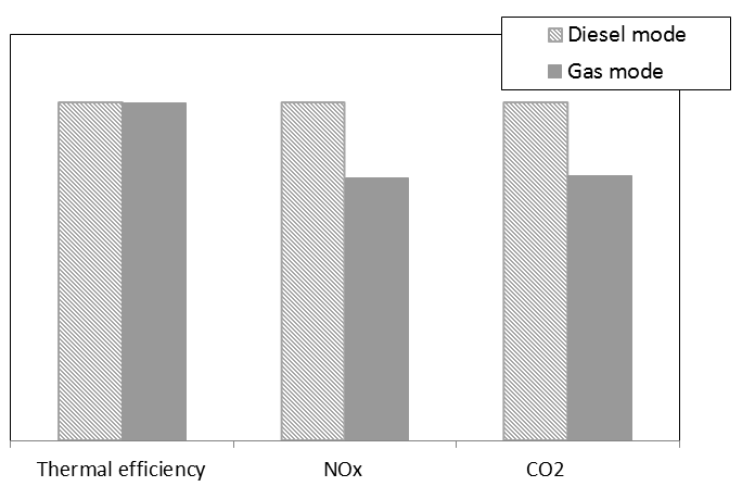

図 9 性能計測結果（75\%負荷） 

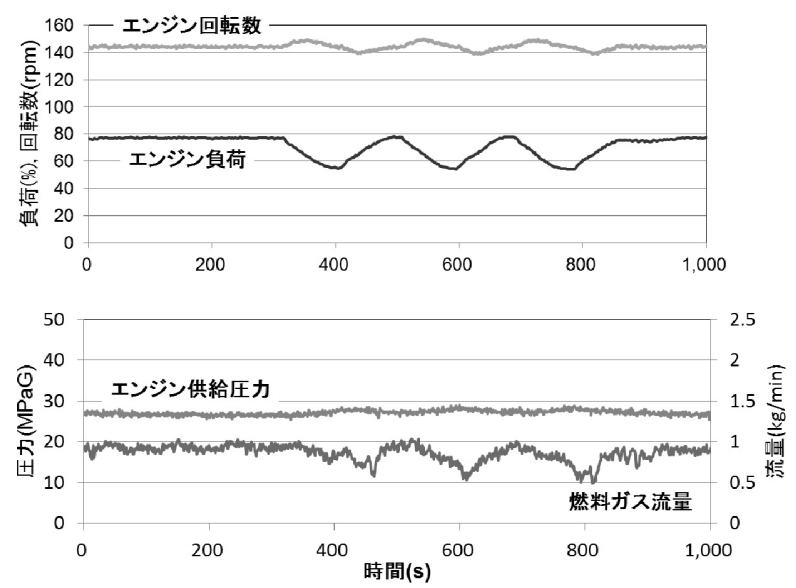

図 10 過渡応答確認結果（負荷変動追従性）
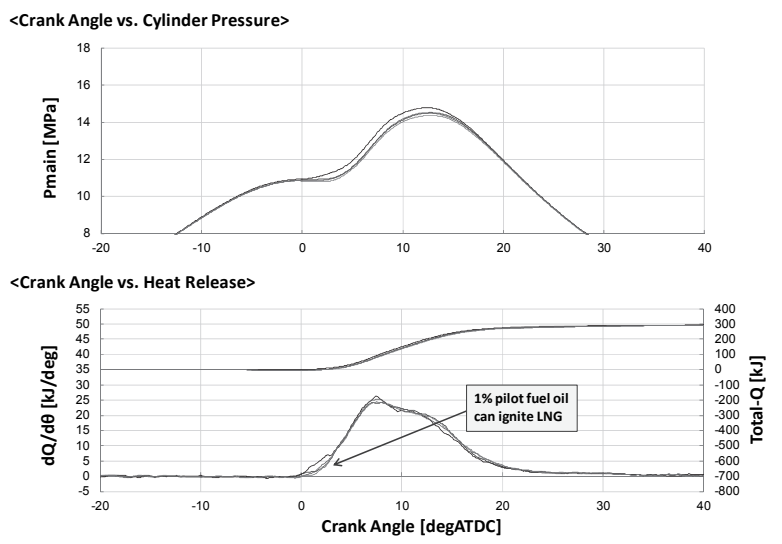

図 11 ガスモードパイロット燃料 $1 \%$ での燃焼状況

\section{5. まとめ}

デュアルフューエル UE 機関”UEC-LSGi”の機関・ システム設計を実施しており，今回の検証運転で UEC-LSGi 機関の $\mathrm{NOx}, \mathrm{CO}_{2}$ 規制に対する大きな優 位性を確認することが出来た. 更に, ガスモードでも 重油焚きディーゼルと同等の高い熱効率が得られてお り, 将来, UEC-LSGi を使用することで, 運航コスト の削減が可能になると考える.

\section{参考文献}

1) Mitsubishi Heavy Industries, Ltd., "MHI to Develop "UEC-LSGi," Low-speed, 2-stroke, Dual-fuel Marine Diesel Capable of Using Natural Gas in Addition to Conventional Heavy Oil Fuel", Press Information No.1555, July 05, 2012

2) Hiraoka, N., Imanaka, K., "Exhaust Emission Control of Mitsubishi UE Diesel Engine", CIMAC Congress 2013, Shanghai, (2013), paper No. 418

3) Takasaki, K., "Japanese National Projects for Global Environmental Protection of the Maritime Sector", Proc. of ISME Kobe, (2011), $\mathrm{KN}-2$.

4) Sakaguchi, K., and Sugihara, M., "The development of the electronically controlled engine, MITSUBISHI UEC Eco-Engine”, CIMAC Congress 2004, Kyoto, (2004), paper No.221

\section{著者紹介}

柳 潤

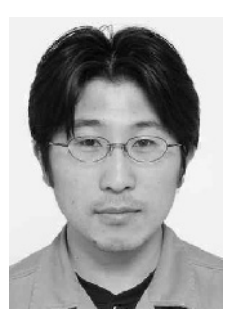

・ 1975 年生.

・ 三菱重工舶用機械エンジン(株)

- 九州大学大学院修士課程

·専門分野 : 機関性能 